\title{
A GÊNESE DA TEORIA DA DEPENDÊNCIA COMO “ANÁLISE CONCRETA DA SITUAÇÃO CONCRETA"
}

\author{
LA GÉNESIS DE LA TEORÍA DE LA DEPENDENCIA COMO “ANÁLISIS \\ CONCRETO DE LA SITUACIÓN CONCRETA"
}

\section{THE GENESIS OF THE DEPENDENCE THEORY AS “CONCRETE ANALYSIS OF THE CONCRETE SITUATION"}

DOI: http://dx.doi.org/10.9771/gmed.v12i2.38038

Raphael Lana Seabra ${ }^{1}$

Resumo: $\mathrm{O}$ presente artigo tem por objetivo lastrear o desenvolvimento inicial das concepções sobre a vertente marxista da teoria da dependência ainda no calor do embate político no Brasil entre 1959 e 1963. O texto se debruça sobre a formação e desenvolvimento da Organização Revolucionária Marxista Política Operária através da análise de alguns documentos políticos da organização, conclui com algumas aproximações desta organização com as contribuições de Lenin em Que Faz̧er?.

Palavras-Chave: Lenin. Política Operária. Teoria da Dependência.

Resumen: Este artículo tiene como objetivo lastrar el desarrollo inicial de las concepciones sobre el vertiente marxista de la teoría de la dependencia aún en plena lucha política en Brasil entre 1959 y 1963. El texto se centra en la formación y desarrollo de la Organização Revolucionária Marxista Política Operária a través del análisis de algunos documentos políticos de la organización, concluye con algunas aproximaciones de esta organización con los aportes de Lenin en ¿Que Hacer?.

Palabras clave: Lenin. Politica Operária. Teoria de la Dependência.

Abstract. This article aims to support the initial development of conceptions about the Marxist side of the theory of dependency still in the heat of the political struggle in Brazil between 1959 and 1963. The text focuses on the formation and development of the Organização Revolucionária Marxista Política Operária through analysis of some political documents of the organization, concludes with some approximations of this organization with the contributions of Lenin in What to Done?

Keywords: Lenin. Política Operária. Dependence Theory.

\section{Introdução}

Em 2020 completam-se 150 anos do nascimento do russo Vladmir Ulianov Lenin, figura incontornável da história mundial do século XX. Mas por que retornar a Lenin em pleno século XXI? E mais, que relações seriam possíveis de se estabelecer entre o revolucionário russo e a Teoria da Dependência, uma das principais contribuições teóricas das ciências sociais latino-americanas? De pronto, duas respostas são possíveis: retornar a Lenin é essencial neste momento como meio de construir alternativas ao capitalismo, num momento em que se considera mais fácil imaginar o fim do mundo do que uma mudança revolucionária em escala mundial mediada pelas revoluções Germinal: Marxismo e Educação em Debate, Salvador, v. 12, n. 2, p.247-259, out. 2020. ISSN: 2175-5604 

nacionais; e, suas relações com a teoria da dependência devem-se ao fato de que assim como Lenin, seus principais autores, não vinham dos círculos de iniciados do Partido Comunista Brasileiro, também representaram o esforço de aplicar o marxismo orginalmente a um contexto do "extremo Ocidente" e ao mesmo tempo de retomar o Que Faz̧er político, de através da análise concreta da situação concreta, ajustar a teoria ao embate político, rompendo com as vacilações, oportunismos e esquerdismos presentes nas organizações políticas dos anos 1960 no Brasil.

O presente artigo tem por objetivo lastrear o desenvolvimento inicial das concepções sobre a vertente marxista teoria da dependência ainda no calor do embate político no Brasil entre 1959 e 1963. Inicialmente, o texto se debruça sobre as caracterizações da Nova Esquerda, para num segundo momento refazer a formação e desenvolvimento da Organização Revolucionária Marxista - Política Operária através da análise de alguns documentos políticos da organização. Ao final, são traçados alguns paralelos entre essa organização e alguns pontos da teoria leniniana da revolução em Que Fazer?.

\section{A Nova Esquerda}

Não há nada de acidental no fato de que a teoria da dependência tenha iniciado seu desenvolvimento no Brasil. Esse fato é evidente se considerarmos que os principais nomes desta corrente sejam brasileiros como Ruy M. Marini, Fernando H. Cardoso, Vânia Bambirra, Theotônio dos Santos, ou como o alemão André Gunder Frank que esteve no país entre 1962 e 1964. Deste modo, é pertinente seria associar as origens da vertente marxista da teoria da dependência à formação da Esquerda Revolucionária no Brasil.

Para melhor compreender o surgimento e formação da Esquerda Revolucionária é necessário destacar as fontes externas e internas ao processo: a) externamente, verifica-se o crescimento do bloco socialista pós-1945, incorporando países com diferentes formações econômico-sociais, possuidores de distintas tradições revolucionárias, confrontados com questões peculiares, que suscitaram variações específicas de aplicação original do marxismo, minando as condições que sustentavam a direção centralizada do movimento comunista. Tal realidade tornou-se irresistível após o processo de desestalinização, mas se viu agravada pelo processo revolucionário chinês, e assume plena significação para a esquerda latino-americana através da Revolução Cubana. Seu impacto se deu em várias direções, como a destruição da tese da conciliação de classes sob a direção política da burguesia nacional, a recolocação do problema da conquista do poder político pelas massas e a radicalização das lutas de classes na América Latina, reabilitou o marxismo na região, liquidando preconceitos sobre sua incompatibilidade com a realidade continental; b) internamente, as mudanças dizem respeito ao maior dinamismo econômico e social que se inicia com o processo de industrialização nos anos 1920. Ainda que o processo de industrialização modifique as posições dos grupos e classes sociais que dele participam, como a relativa crise do setor latifundiário-exportador

Germinal: Marxismo e Educação em Debate, Salvador, v. 12, n. 2, p.247-259, out. $2020 . \quad$ ISSN: 2175-5604 
e a participação direta da burguesia industrial no bloco do poder, a participação e os benefícios para as classes trabalhadoras urbanas e rurais resultantes de tal processo são bastante desiguais. Sem a transformação efetiva da estrutura fundiária e o enfrentamento consequente do papel do capital estrangeiro no país, a industrialização tendeu a aprofundar suas tendências concentradoras de renda e de maior exploração do trabalho. Tais características fizeram com que nos anos 1960 a inquietação social no país crescesse em razão direta do processo de desenvolvimento capitalista, gerando um clima de reivindicações econômicas e de crises políticas cada vez mais acentuadas. Em paralelo, o ambiente político e intelectualmente instigante de combate às concepções liberais, abriram espaço para o debate público sobre a modernização e o desenvolvimento, influenciando não apenas as posições políticas reformistas, mas também formando uma jovem intelectualidade não filiada a tais partidos. A crise político-ideológica do PCB acelerou a desorganização nos meios de esquerda, mas permitiu o retorno às fontes marxistas, cirando condições para leituras originais da realidade brasileira pelas novas organizações (POLOP, 1963, p.28-29).

É neste contexto complexo que se dá o surgimento da Esquerda Revolucionária que define o conjunto de grupos ou organizações que em resposta ao reformismo do PCB e do PTB adotam como denominador comum o caminho da insurreição como única via para a revolução. É rompida a tese política de conciliação com as frações industriais da burguesia e reivindicada a plena e completa autonomia organizativa e política do movimento proletário frente à burguesia. Trata-se, portanto, de um degelo teórico que, na prática, se materializa na formação de novos agrupamentos de esquerda, que afloram na vida política, com maior ou menor prazo de vida. A proliferação de novos agrupamentos de esquerda se dão de duas maneiras: pela cisão de organizações já existentes (caso do PCB) e pela constituição de grupos novos, e resulta das opções que o debate coloca aos indivíduos ou setores de organizações mais antigas e as jovens que despertam para a atuação revolucionária (POLOP, 1963). Em síntese a maioria dos grupos, organizações e partidos da Esquerda Revolucionária concluíam a falta de vocação revolucionária da burguesia brasileira, recusando qualquer perspectiva de caminho gradual e pacífico para o socialismo (BAMBIRRA, 1972).

A definição mais ampla das novas organizações como Esquerda Revolucionária e suas divisões internas estabelecida por Vânia Bambirra (1972, p.52-71) em pró-chineses, foquistas e a nova esquerda, sem dúvida ganha em sofisticação. Nesse sentido, a autora define a Esquerda Revolucionária como o conjunto de novos agrupamentos de esquerda cujo denominador comum encontra-se no fato de, em resposta ao reformismo do PCB, colocarem a via insurrecional como única via para a revolução. Porém, existem no interior dessas organizações diferenças substantivas no que diz respeito à definição do caráter da revolução, o modo de conceber as formas adotadas pela via insurrecional e, consequentemente, a orientação de sua atividade prática. A autora ainda adverte que estas novas organizações passam longe do purismo, posto que houve a circulação relativamente intensa de militantes entre estes três tipos de organização, provocada tanto pelas debilidades de 
explicitação de uma coerente linha teórico-prática, como pela existência de uma concepção empirista e imediatista, da convicção de parte da militância de seguir junto sempre daquela organização que transparecesse uma posição mais combativa (BAMBIRRA, 1972, p.52-53).

Vale destacar que as análises de Bambirra não se limitam apenas às organizações brasileiras, senão que as estendem a toda a América Latina. Destacamos aqui a definição da autora da Nova Esquerda. Está é formada por organizações que se surgidas em oposição teórica à linha política dos PC's. Colocavam como objetivo inicial fundamental a constituição como vanguarda da luta ideológica contra o reformismo, para posteriormente criar um Partido revolucionário que se apresentasse como alternativa real diante dos partidos reformistas, e avançar as lutas de classes, preparando as condições para insurreição popular. A nova esquerda concebia o caráter da revolução como socialista, e por sua vez, anti-imperialista e anticapitalista, conduzida pela aliança operáriocamponesa, sob a liderança da classe operária. Na maior parte das vezes, essas organizações eram formadas por jovens estudantes independentes, poucos trotskistas e dissidentes do PC e dos partidos populistas. Estas organizações tinham por característica uma visão de conjunto do processo econômico e político, justamente pelo esforço de aplicar cariativamente o marxismo às novas condições do capitalismo dependente, o que se refletia no seu rechaço ao imediatismo da luta - em oposição ao foquismo -, por sua preocupação com a formação de quadros políticos e na importância conferida à luta política e à elaboração de uma estratégia revolucionária adequada à situação do continente (BAMBIRRA, 1972, p.58).

\section{A POLOP: em busca da aplicação original do marxismo à realidade brasileira}

O aprofundamento da crise do capitalismo brasileiro em fins dos anos 1950 demandava um novo marco para a compreensão da realidade, articulando as situações nacional e internacional, quer dizer, situando a dinâmica do capitalismo brasileiro no interior do sistema imperialista, como parte da divisão internacional do trabalho. A elaboração deste novo marco de interpretação do capitalismo brasileiro estava diretamente relacionada à conjuntura dos anos 1950-1960, quer dizer, a crise estrutural do próprio desenvolvimentismo que se delineava na elevação da inflação como mecanismo de acumulação das burguesias, a insatisfação popular frente ao aumento do desemprego, o surgimento de um movimento camponês organizado pondo em xeque a estrutura da propriedade da terra, as recorrentes greves contra a perda do poder de compra dos salários, questões que obrigavam à redefinição política e organizativa da esquerda brasileira, à leitura mais detida da nova fase do capitalismo no país e suas contradições fundamentais.

Nesse sentido, havia a sensibilidade de parte da militância daquela época - seja a militância independente ou a dissidente dos partidos até então existentes - da centralidade da tarefa de renovação teórico-política do campo de esquerda e de articular esse campo no sentido da construção de uma alternativa ao reformismo, à conciliação de classes sob a direção da grande

Germinal: Marxismo e Educação em Debate, Salvador, v. 12, n. 2, p.247-259, out. 2020. ISSN: 2175-5604 

burguesia industrial. De acordo com Luiz Alberto Moniz Bandeira, após a formação da Liga Socialista Independente (LSI) em São Paulo em 1956, e da Juventude Socialista (JS-PSB) no interior do Partido Socialista Brasileiro em 1957 no Rio de Janeiro (Bandeira, 2017, 12), foi decidido que naquele momento o instrumento político de renovação do marxismo e aglutinação da esquerda se efetivaria na publicação da Revista Movimento Socialista, que teve dois números publicados em 1959. Essa revista obteve certa repercussão, aglutinando não apenas grupo luxemburguista da LSI de São Paulo, e a JS-PSB do Rio de Janeiro, mas atraindo também grupos dissidentes do trabalhismo em Minas Gerais, além de outros militantes independentes, como por exemplo, da Escola Brasileira de Administração de Pública (EBAP).

A partir da recepção positiva da revista e da ampliação dos contatos foi redigida por Eric Sachs a convocatória em julho de 1960 para o I Congresso que ocorreria em fevereiro de 1961, no interior de São Paulo. Ainda seriam realizados mais três congressos em 1962, 1963 e 1967, quando a organização se converte em Partido Operário Comunista $\left(\mathrm{POC}^{2}\right)$ devido às profundas divergências quanto ao papel a ser desempenhado ou não pela luta armada, dando fim a formação original polopista. As teses da nova organização eram influenciadas por referências diversas, desde Nikolai Bukhárin, Rosa Luxemburgo e Vladmir Lenin até intelectuais menos conhecidos no país como dois ex-militantes da Liga Spartakista alemã Heinrich Brandler e August Talheimer, e posteriormente da Oposição Comunista Alemã e caracterizada por sua autonomia criadora de uma elaboração original (Cf. MEYER, 2009a).

Sua militância era formada basicamente por jovens intelectuais, estudantes, militares de baixa patente e, em menor número de operários industriais. De acordo com Marini (2012), sem dispor de aparatos armados e carente de uma base proletária significativa, a organização buscou amparar-se em seus princípios, em sua capacidade de produção teórica para lograr se afirmar no seio da esquerda. Esse fato levantou uma série de críticas ao suposto intelectualismo da organização, porém, a maior limitação da organização para favorecer a aglutinação da esquerda revolucionária, resultou principalmente de sua incapacidade de aprofundar seus acertos teóricos e convertê-los numa estratégia global de ação, que respondesse às exigências da luta de classes em nível político e militar.

$\mathrm{Na}$ Convocatória para o $1^{\circ}$ Congresso da Polop de 1960, logo no primeiro parágrafo encontramos a exortação de que "chegamos à conclusão de que a tarefa principal dos marxistas brasileiros consiste na formação de um partido independente da classe operária" (SACHS, 2009 [1960], 21). Colocando a questão de que os partidos que deveriam se prestar a esse papel não preencheram a função de defesa dos interesses da classe trabalhadora, quer dizer, o PCB não se converteu no partido operário, como também o PSB e o $\mathrm{PTB}^{3}$. A convocatória levanta duas questões recíprocas: como chegar ao dito partido nas condições concretas das lutas de classes no país, e qual a forma o partido tomará sob essas condições? Ainda que existisse naquela conjuntura uma vastidão de militantes de esquerda que buscassem um campo de ação, com composição heterogênea e praticamente unidos 
pela crítica à linha do $\mathrm{PCB}^{4}$, as divergências eram profundas: desde uma parca preocupação com o problema do marxismo no Brasil, ou a adoção de esquemas prontos e elaborados trazidos de fora, tal como o da revolução chinesa, mas também aqueles que refutam a cópia de qualquer modelo revolucionário precedente.

Tal palavra de ordem, no contexto de sua redação tem consequências políticas e teóricas fundamentais de amplo alcance ao definir: a) que a tutela e domínio burgueses sobre o proletariado se expressam materialmente pela legislação sindical e outros aparelhos de repressão; e, b) ideologicamente pelas teorias que pregam a comunidade de interesses entre a burguesia e o proletariado (nacionalismo, desenvolvimentismo), que têm como consequências o sacrifício das reivindicações próprias do proletariado.

O documento da Convocatória... tem consciência de que não se trata de fundar apenas mais um sigla, mas de criar as condições desde o novo instrumento político para a construção de um partido proletário efetivamente orgânico. Essa tarefa de construção não resultará da simples elaboração de um documento e um estatuto, mas da formação de quadros com habilidade de estudar e interpretar a realidade brasileira sob um ângulo marxista, de analisar a situação mundial e assimilar boa parte da experiência da luta de classe em escala internacional (Cf. SACHS, 2009 [1960]). Essa perspectiva é mais bem desenvolvida no texto $O$ nome e um Programa em que se apresentava o primeiro número do Jornal Política Operária em janeiro de 1962. Segundo o texto a renovação da esquerda dependeria:

De aplicar o método do marxismo naquilo que comumente se chama realidade
brasileira. [...] O marxismo, onde abalou o mundo, foi antes de tudo criador. A
falta de uma aplicação construtiva do marxismo e das experiências do
movimento internacional à realidade do país fez com que a esquerda,
finalmente, se limitasse a desempenhar suas atividades não em função da sua
classe operária e dos seus objetivos históricos, mas sim como apêndices da
política externa de países que já realizaram suas revoluções (POLOP, 1962, 2-3).

Vemos aqui a crítica direta a um dos equívocos do PCB de simplesmente copiar e tentar implementar modelos revolucionários exteriores à realidade brasileira. Essa crítica será continuada na redação sofisticada em Dialética da Dependência de Ruy Marini, quando este afirma que diante do parâmetro puro do modo de produção capitalista, a economia latino-americana apresenta peculiaridades que às vezes são dadas como insuficiências e outras como deformações. Para a Polop a independência organizativa do proletariado deveria se livrar do duplo espectro de dominação: internamente da coalização nacional-desenvolvimentista, e externamente da rigidez das determinações do Comitê Executivo da Internacional Comunista.

Ainda que existissem críticas isoladas à sobrevivência de resquícios feudais e à externalidade do imperialismo à realidade brasileira, até os anos 1960, a tese do porvir da revolução democrático-burguesa se manteve hegemônica na esquerda. A insistência sobre a importância do debate teórico e da formação de seus quadros, a ponto de forjar uma linguagem comum, não resulta de qualquer preciosismo teórico, intelectualismo ou elitismo, mas de perseguir a máxima leniniana de que 
“sem teoria revolucionária não pode haver também movimento revolucionário" (LÊENIN, 1977, p.96-97). O aprofundamento da crise do nacional-desenvolvimentismo em 1963 colocava em evidência os resultados políticos da insuficiência teórica do movimento revolucionário no país. Nas teses aprovadas em seu II Congresso de 1963, a organização avalia três problemas da esquerda resultantes de suas insuficiências teóricas: a) a incapacidade que demonstra em definir com precisão a fase que a atravessa a realidade brasileira e, consequentemente, as tarefas a realizar; b) evidencia-se no esquematismo e no dogmatismo, como também no baixo nível das discussões internas ou entre as organizações; e, c) no despreparo de seus quadros e na carência do trabalho interno de formação para superar tal inconveniente (POLOP, 1963, 27).

Com a crise econômica e política brasileira, ganham maior força as preocupações sobre a forma de se organizar e se fortalecer internamente, sobretudo, a clareza de que aquele ano - 1963 poderia ser o momento de maior amadurecimento de um projeto independente da classe trabalhadora, de formação de uma Frente dos Trabalhadores da Cidade e do Campo ${ }^{5}$, quer dizer, denunciar a política de colaboração de classes, defendida pelos partidos reformistas e nacionalistas, que colocavam o conjunto dos explorados e exploradas sob a condução do bloco burguês no país (POLOP, 1963a, p.7).

O documento é aberto com a crítica direta ao colaboracionismo de classe propagado pelo PCB, de que no interior da reorganização do sistema interimperialista, haveria certo conflito entre a burguesia nacional e o imperialismo. Essa leitura equivocada teria levado o PCB a estabelecer um plano de apoiar a burguesia nacional, abandonando qualquer pretensão de dirigir o movimento operário autonomamente. Por outro lado, a organização tem plena convicção de que a ação independente das massas exploradas e dominadas pela burguesia, na conjuntura dos anos 1960, era inviável sem a ação conjunta da esquerda. Outra vez, defende-se a proposta da autêntica Política Operária, considerando que o partido como instrumento político surgiria não só da organização de seus quadros mais conscientes, mas principalmente da luta diária das massas e em proveito das mesmas, como elemento aglutinador do conjunto da esquerda ${ }^{6}$ e em melhores condições para participar das lutas e orientá-las na direção de uma verdadeira luta de classes (POLOP, 1963a, p.7).

Ainda que não seja possível aprofundar todos os pontos trazidos pelas diretrizes e teses aprovadas nos documentos do II Congresso de 1963, ele aborda a crise brasileira de modo bastante original, ao situar a crise do capitalismo como situação inédita no país devido às condições internas desta, desligadas de uma crise capitalista internacional de maiores proporções. É notável que haja apenas uma menção à noção de dependência, quando refere-se aos limites de produtividade do imperialismo dado o "baixo consumo das áreas dependentes" (POLOP, 1963a, p.11). Ainda que haja certo otimismo em relação à situação internacional de crescimento do bloco socialista, de que a revolução mundial estaria a alguns passos daquela conjuntura, a relação dialética com o sistema imperialista, como mencionado não se dava num contexto de crise capitalista mundial, mas do novo papel desempenhado pelo imperialismo na economia brasileira, de como a nova fase da 

formação econômico-social brasileira.

De acordo com as Perscpetivas das Lutas de Classes no Brasil- Teses Aprovadas no II Congresso, o processo de desenvolvimento capitalista brasileiro ganha impulso a partir da segunda metade do século XIX, com a guerra do Paraguai e com a abolição da escravidão, mas acelera-se a partir da desorganização do sistema capitalista mundial com a Primeira Guerra Mundial de 1914. Desde então, a nascente burguesia industrial começa a disputar o aparato político com o setor oligárquicolatifundiário. Tal situação só encontra solução com a Crise de 1929 e a Revolução de 1930. O compromisso de 1937 representa a solução bonapartista na ditadura de Getúlio Vargas encontrada pela burguesia para garantir sua permanência no poder e para criar condições estáveis para seu desenvolvimento. A questão é que a partir do segundo Governo de Getúlio Vargas, os conflitos da burguesia industrial com o setor latifundiário e a crise deste setor exigem a revisão do compromisso de 1937. A primeira revisão deste compromisso desenvolve-se ao longo do governo de Juscelino Kubitschek, de modo que a "revisão constituiu, basicamente, em arrogar-se à burguesia o direito de mobilizar as disponibilidades internas e externas do sistema para a implantação da indústria de base, sem prejuízo dos privilégios concedidos aos latifundiários e grupos comerciais nacionais e estrangeiros vinculados à exportação" (POLOP, 1963b, p.21). A consequência da revisão foi não apenas o crescimento da burguesia industrial e financeira, mas seu entrelaçamento com o capital estrangeiro em caráter ainda mais radical. Nesse sentido, a crise de crescimento brasileira, abre uma nova perspectiva para as lutas de classe no país, é lida como crise da industrialização ou também crise do nacional-desenvolvimentismo (POLOP, 1963a, p.8).

Nesse sentido, o processo de crescimento capitalista coloca a fração burguesa sobretudo paulista - como fração hegemônica no interior do bloco burguês, de modo, que não se trata mais de uma classe alijada ou sócia menor no plano político. A crise da industrialização por substituições de importações levanta uma aparente crise entre a burguesia nacional, o sistema latifundiário e a burguesia imperialista, crise esta que tem sua revisão confiada ao governo de Jânio Quadros que instaura a "política de autoridade". Dado o desgaste da inflação como parte da acumulação capitalista, o ascenso do movimento de massas, o exemplo próximo da Revolução Cubana e as limitações do mercado interno dada a própria peculiaridade do desenvolvimento capitalista periférico, a revisão da crise começou pelo esforço de uma política externa independente, pelo anúncio de algumas reformas estruturais (reformas de base) - que desencadeou a reação das demais frações dominantes da burguesia.

O desfecho foi a crise política aberta em agosto de 1961 com a renúncia de Quadros, e o ensaio de golpe contra o então vice-presidente João Goulart, ex-ministro do Trabalho de Getúlio Vargas (1953-1954), um Trabalhista identificado com o sindicalismo. Em seu fracassado intento golpista, Quadros julgava que os militares impediriam a posse de Goulart, como também imporiam seu mandato à Câmara sob o suposto "clamor popular". Na realidade não houve qualquer 

legalidade convocada pelo governador do Rio Grande do Sul, Leonel Brizola, despontou várias manifestações no país foram para defender a posse de Goulart como presidente, diante de ameaças de veto militar e de outros setores e partidos conservadores, como a União Democrática Nacional (UDN). Goulart assumiria a presidência em setembro de 1961. Essa crise político-econômica levou as massas urbanas a maior radicalização e diante o intento de intervenção popular na vida política do país, a classe dominante recua através da emenda parlamentarista, onde Goulart assume o governo numa forma de presidencialismo enfraquecido. A radicalização popular e o exemplo próximo da Revolução Cubana levaram vários setores da esquerda a descuidar das tarefas de organização e permitir que os acontecimentos ocorressem livremente.

Frente à análise conjuntural realizada pelas resoluções e teses do II Congresso, nos deparamos novamente com o problema teórico levantado por seus quadros desde 1959: de um lado o oportunismo, entendido como atuação política sem diretrizes próprias, realizada ao sabor das circunstâncias dadas pela marcha do processo político e a reboque dos grupos ou classes que desenvolvem uma ação deliberada conforme seus próprios objetivos; de outro, o aventureirismo, como a atuação política irracional, sem base no conhecimento objetivo das condições em que os fatos se desenvolvem, mas antes disso, orientada subjetivamente, mais pelo desejo de seus condutores do que pela realidade (POLOP, 1963b, 27). Desse modo, o plebiscito de reestabelecimento de plenos poderes presidenciais a Goulart foi lido pelo desvio oportunista como vitória da pressão popular, na luta pela manutenção da ordem legal e democrática. Todavia, tratavase de uma aparente vitória, pois ela tinha como razão de fundo a preocupação de setores conservadores em relação as eleições de 1965 - de modo que o plebiscito foi antecipado para 1963 por pressão destes setores, antecipando os riscos de assumir um executivo com poderes limitados.

A Polop considera no documento que o apoio dado ao plebiscito pelo PCB e percebido por este como uma saída progressista - caso evidente da política colaboracionista entre burguesia e proletariado -, que na realidade abriu margem para que a burguesia industrial se aproximasse de João Goulart e que as Reformas de $\mathrm{Base}^{7}$ fossem realizadas não para o campo popular, mas como parte de estabilização da crise do capitalismo brasileiro. Enquanto Goulart representasse a possibilidade de contenção do movimento popular, este representaria outro ensaio de bonapartismo para a burguesia, evitando, portanto a ditadura direta.

A luta anti-imperialista consequente simplesmente quer dizer que a destruição da ingerência imperialista, do inimigo principal, passa obrigatoriamente pela destruição do capitalismo nacional, tanto da grande burguesia industrial, como da latifundiária, do inimigo imediato - esta é outra grande questão levantada posteriormente pela vertente marxista da dependência ${ }^{8}$. 
Existem certas coincidências entre as teses leninianas de 1902, mais especificamente, aquelas desenvolvidas em Que Faz̧er? e as teses polopianas dos anos 1960. Isso não quer dizer a transplantação de concepções teóricas de outras latitudes e tempos, mas no fato de que a universalidade da contribuição leniniana reside em seu método de explicação e de atuação que tem de ser recriado, aplicado criativamente, em função de cada situação específica (BAMBIRRA e SANTOS, 1981). Portanto, a organização apostava em algo central para Lenin, que o ligava diretamente a Marx: na atualidade da revolução (Lukács, 2012), tornar o socialismo questão principal para os Trabalhadores da Cidade de do Campo. Aqui não é possível explorar todas as similaridades, mas nos parece importante indicar as mais significativas.

No livro, Lenin expressa inúmeras vezes o fato de que a força do movimento da virada de século consistia no "despertar das massas (principalmente do proletariado industrial) e a sua debilidade na falta de consciência e de espírito de iniciativa dos dirigentes revolucionários” (LENIN, 1977, p.99). Diante da ascensão do movimento popular era necessário constituir não só os instrumentos políticos, mas também os instrumentos teóricos necessários capazes de levar à revolução social na Rússia. Nesse sentido, no livro encontramos críticas à penetração acelerada do reformismo na Rússia, através das revisões de Eduard Bernstein, expressadas nas vertentes economicistas e no marxismo legal que simplificavam as ideias marxianas; o esforço em unificar os grupos social-democratas e levar a cabo uma dura polêmica contra as correntes oportunistas; a defesa da fusão do movimento operário com o socialismo, o partido como instrumento de formação, luta e representação dos interesses do movimento nacional-popular em seu conjunto, salvaguardando sua independência política e ideológica. De modo que lançada à própria sorte as massas não seriam capazes de ir além dos interesses imediatistas (salariais, sindicais), como também inexistia um partido capaz de agir como líder e catalisador de um movimento já existente, como corporificação de uma tendência que molda o movimento revolucionário dos operários russos (BAMBIRRA e SANTOS, 1981; KRAUSZ, 2017). A questão é que diante da ascensão das massas e da própria difusão do marxismo na Rússia foram acompanhadas do rebaixamento do nível teórico. Lenin defende que a importância da teoria por três razões: 1) dada a incipiência do próprio partido, que apenas começa a elaborar sua fisionomia e ainda estava longe de ajustar as contas com outras tendências do pensamento revolucionário que desviavam o movimento da revolução; 2) o movimento socialista é, por sua própria natureza, internacional. Significa que este movimento incipiente num país jovem só pode se desenvolver com êxito desde que a aplique a experiência de outros países, assumir uma postura crítica diante dessa experiência e comprová-la por si próprio; 3) social-democracia russa tem as tarefas nacionais que nunca teve nenhum outro partido socialista do mundo, como derrubar o último bastião do absolutismo. Em síntese, Lenin postula que a grande luta do partido é dividida em três formas: a política, a econômica e a teórica (LENIN, 1977).

Germinal: Marxismo e Educação em Debate, Salvador, v. 12, n. 2, p.247-259, out. $2020 . \quad$ ISSN: 2175-5604 
Como vimos ao longo do artigo existem circunstâncias que aproximam as realidades e que sugerem que a POLOP buscou configurar o que fazer no contexto nacional. Havia clara percepção da penetração de que o marxismo, o socialismo haviam se difundido e penetrado rapidamente desde os anos 1950, mas esta também veio acompanhada do rebaixamento teórico; a defesa da organização política independente da classe trabalhadora, de ir além dos interesses mais imediatos desta; o esforço em constituir Frentes capazes de unificar o movimento popular na direção da revolução social; a importância do partido como instrumento de formação e aplicação orginal do marxismo, conferindo ao problema teórico importante papel na concepção da organização; ao fim, inexistia a pretensão da POLOP em se arrogar a vanguarda, esta capacidade de direção seria resultante da análise concreta da situação concreta, do talento dos quadros partidários em agirem como líderes e catalisadores de um movimento já existente, pela flexibilidade das formas de luta. A POLOP ressignifica o leninismo pela reinvenção do projeto revolucionário nas condições do imperialismo e da dependência, de maior agressividade das burguesias.

A releitura dos documentos da Polop é fundamental para a reconstrução da trajetória da vertente marxista da dependência. A forma original com que a organização aplicou o marxismo à realidade brasileira - repetição da ação leniniana - permitiu não apenas acertos políticos bastante precisos sobre a conjuntura dos anos 1960 e o que fazer político, mas também muniu alguns de seus militantes do arsenal teórico-conceitual para sistematizações e elaborações posteriores que foram fundamentais às ciências sociais. Ao final, é evidente que alguns conceitos e categorias fundamentais da teoria da dependência integram as resoluções, análises e o programa polopiano: dialética da integração periférica ao sistema mundial; a natureza capitalista do latifúndio; a associação de interesses entre a burguesia local e o imperialismo; a inviabilidade de reformas no capitalismo dependente; as soluções de força para recomposição do esquema de dominação; o esforço do capitalismo brasileiro em sair da crise pela conquista de mercados externos para sua produção industrial; a tendência estrutural dos níveis de desemprego; maior exploração e pauperização do conjunto da classe trabalhadora.

\section{Referências:}

BAMBIRRA, Vânia y SANTOS, Theotônio. La estrategia y la tactica socialistas de Marx y Engels a Lenin. Tomo 2. México: Ediciones ERA, 1981.

BANDEIRA, Luis Alberto Moniz. 2017. "Notas sobre a POLOP e Eric Sachs". Revista Espaço Acadêmico, ano XVI, n¹88, p.1-37. Disponível em http://periodicos.uem.br/ojs/index.php/EspacoAcademico. Acesso em: 05.07.2017

KAMEYAMA, Ceici e STOTZ, Eduardo. 2016. “A formulação do Programa Socialista para o Brasil e o caminho da independência de classe: contribuições de Érico Sachs” In Érico Sachs/Ernesto Martins um militante revolucionário entre a Europa e o Brasil, editado por Sérgio Paiva, 29-72. Salvador: CVM.

KRAUSZ, Tamás. Reconstruindo Lenin. Uma biografia intelectual. São Paulo: Boitempo, 2017. 

brasileira. Pará de Minas, MG: Virtual Books.

LENIN, Vladmir. “Que fazer? Problemas candentes do nosso movimento” In: LENIN, Vladmir. Obras Escolhidas vol.1. Moscou: Progresso/ Lisboa: Avante, 1977.

LUKÁCS, György. Lenin: um estudo sobre a unidade de seu pensamento. São Paulo: Boitempo, 2012.

MARINI, Ruy Mauro. 2005. "Memória” In. Ruy Mauro Marini: vida e obra, editado por João Pedro Stédile e Roberta Traspadini, 57-135. São Paulo: Expressão Popular.

MARINI, Ruy Mauro. 2012. Subdesenvolvimento e Revolução. Florianópolis: Insular.

MEYER, Victor. 2009. "Ernesto Martins, Érico Czaczkes Sachs”. In: Centro de Estudos Victor Meyer (org.). Polop. Uma trajetória de luta pela organização independente da classe operária no Brasil, editado por Centro de Estudos Victor Meyer, 15-20. Salvador: Artetexto.

MEYER, Victor. 2009a. "Frágua inovadora: o tormentoso percurso da Polop." In: Polop. Uma trajetória de luta pela organização independente da classe operária no Brasil, editado por Centro de Estudos Victor Meyer, 265-278.Salvador: Artetexto.

SACHS, Eric. 2009 [1960]. "Convocatória para o $1^{\circ}$ Congresso da POLOP.” In Polop. Uma trajetória de luta pela organização independente da classe operária no Brasil, editado por Centro de Estudos Victor Meyer, 21-32. Salvador: Artetexto.

SACHS, Eric. 2016 [1982]. "O PSB e a fase atual da Luta de Classes” In Érico Sachs/Ernesto Martins um militante revolucionário entre a Europa e o Brasil, editado por Sérgio Paiva, 317-323.

Salvador: CVM.

\section{Fontes}

Política Operária. Jornal Política Operária n¹ ano I, janeiro de 1962.

Política Operária. “O Caminho da Crise Brasileira." In Revista Política Operária n6, março-setembro de 1963.

Política Operária. "Diretrizes para uma Política Operária." In Revista Política Operária n6, marçosetembro de 1963 a.

Política Operária. "Perspectivas da Luta de Classes no Brasil. Tese Aprovada no II Congresso." In Revista Politica Operária nº, março-setembro de 1963b. ${ }^{9}$

\footnotetext{
Notas

1 Professor no Departamento de Estudos Latino-Americanos (ELA) e do Programa de Pós-Graduação em Ciências Sociais e Estudos Comparados sobre as Américas (PPG-ECsA) da Universidade de Brasília (UnB). É autor do livro "A Via Venezuelana Ao Socialismo" (2014) e organizador e autor de "Dependência e Marxismo: contribuições ao debate crítica latino-americano" (2016). É pesquisador e líder no Grupo de Estudos sobre Pensamento Crítico Latino-Americano (ECLA). Currículo Lattes: http://lattes.cnpq.br/8005319733852567; ORCID: https://orcid.org/0000-0003-1203-8965, e-mail: raphaelseabra@hotmail.com

2 Dada a impossibilidade em reproduzir a história detalhada de ascensão e crise da organização, a composição de seus quadros militantes e sua inserção na cena política, para aprofundamentos sugerimos Meyer (2009), Leal (2014) e Kamayama e Stotz (2016).

3 Quer dizer, eram todos partidos de massas, com importante presença nos meios sindicais rurais e urbanos, com capacidade de agitação e organização, mas amparados na disputa pelo enorme prestígio e popularidade do trabalhismo varguista, sobretudo em seus aspectos nacional-desenvolvimentistas, de defesa das riquezas nacionais e do antiimperialismo. Era praticamente um frente única das forças sociais (proletariado, campesinato, pequena burguesia urbana, burguesia industrial e até parte do latifúndio descontente com o imperialismo).
} 
4 Existe sempre o risco de simplificar o PCB como grande bloco monolítico. Internamente as disputas não eram "novidades", desde o Manifesto de Agosto de 1950, quando na esteira da Revolução Chinesa era colocada uma posição favorável à luta armada, conduzida por um exército de libertação nacional, como também nas críticas à posição antigetulista, taxado como governo de "traição nacional", passando pela campanha do "voto em branco" em 1954, mas sobretudo, as autocríticas, ressentimentos e depeceções acentuam-se após o XX Congresso Partido Comunista da União Soviética, quando Nikita Kruschev denuncia os crimes de Stálin.

5 A Frente era o meio de se opor à "frente única com a burguesia" preconizada pelo PCB, PDT e PSB, mas sem excluir tais partidos. A frente teria condução hegemônica proletária, mas seria composta por trabalhadores urbanos, campesinato, movimento estudantil, pequena burguesia e soldados, cabos e marinheiros de origem popular.

${ }^{6}$ A formação da Frente da Esquerda Revolucionária reunindo esforços com as novas organizações como o Partido Comunista do Brasil (PCdoB) e o Movimento Revolucionário Tiradentes (MRT) (Polop, 1963, 7).

${ }^{7}$ O programa das Reformas de Base passava pelas reforma agrária, bancária, tributária, urbana, eleitoral, do estatuto do capital estrangeiro e universitária.

8 Qualquer semelhança entre a concepção polopista sobre o anti-imperialismo consequente e a proposição de André Gunder Frank no artigo de 1968, Latinoamérica: Subdesarrollo capitalista o revolución socialista, não é mera coincidência. Frank durante sua passagem pela Universidade de Brasília, inclusive participou de reuniões da direção da Polop, incorporando as teses da organização à sua crítica prévia ao desenvolvimentismo funcionalista (Marini, 2005; Leal, 2014)

Recebido em: 23.07.2020

Aprovado em: 25.08.2020 